Ann. Biol. anim. Bioch. Biophys., 1979, 19 (5), 1435-1442.

\title{
Application of a simulation method for the study of beginning growth in ovarian follicles
}

par J. C. MARIANA, J. A. MEYER *

Station de Physiologie de la Reproduction, I. N. R. A., Nouzilly, 37380 Monnaie.

* INSERM, U123, 44 Chemin de Ronde, 78110 Le Vesinet, France.

Summary. Using simulation methods applied to two mathematical methods, we have attempted to show that the existence of only one follicular stock of less than $1259 \mu^{2}$ was not compatible with the structure of the follicular population observed in adult animals. On the other hand, a stock containing several series of follicles classified according to size and to aptitude for the initiation of growth, accounted for the unimodal structure of the growing follicle population in adults.

A study of mathematical models capable of describing the structure of the ovarian follicle population led us to define three important factors (Mariana and Millier, 1977) : 1) initiation of growth in small follicles with one layer of cells surrounding the oocyte ; 2) follicular growth by granulosa cell multiplication, increase in oocyte size and formation of the antrum ; 3) follicle disappearance due to atresia or ovulation.

Faddy, Jones and Edwards (1976) proposed a compartmental model for the female rat to estimate rates of the entry and the exit of follicles at each growth stage. These authors showed that the model gave a good idea of the overall change in the number of follicles in the ovary throughout the life of the rat, as well as of the large variability in follicle transition time in each compartment.

The direct study of folliculogenesis by analyzing the distribution of ovarian follicles in relation to their size, number of granulosa cells or any other parameter, has been little developed. Paesi (1949) was the first to attempt such a study, but the difficulty in counting ovarian follicles was undoubtedly a limiting factor.

The interpretation and statistical analysis of such distributions are difficult since the number of follicles present in the successive classes are not independent variables (Faddy, 1976) in terms of time. The distribution of growing follicles at a given time in the life of an animal is, in fact, an instantaneous realization of follicular renewal and growth in the ovary.

We have attempted to determine whether, taking the model of Read (1968) as a starting point, a computer simulation of that process could, at a given moment, give 


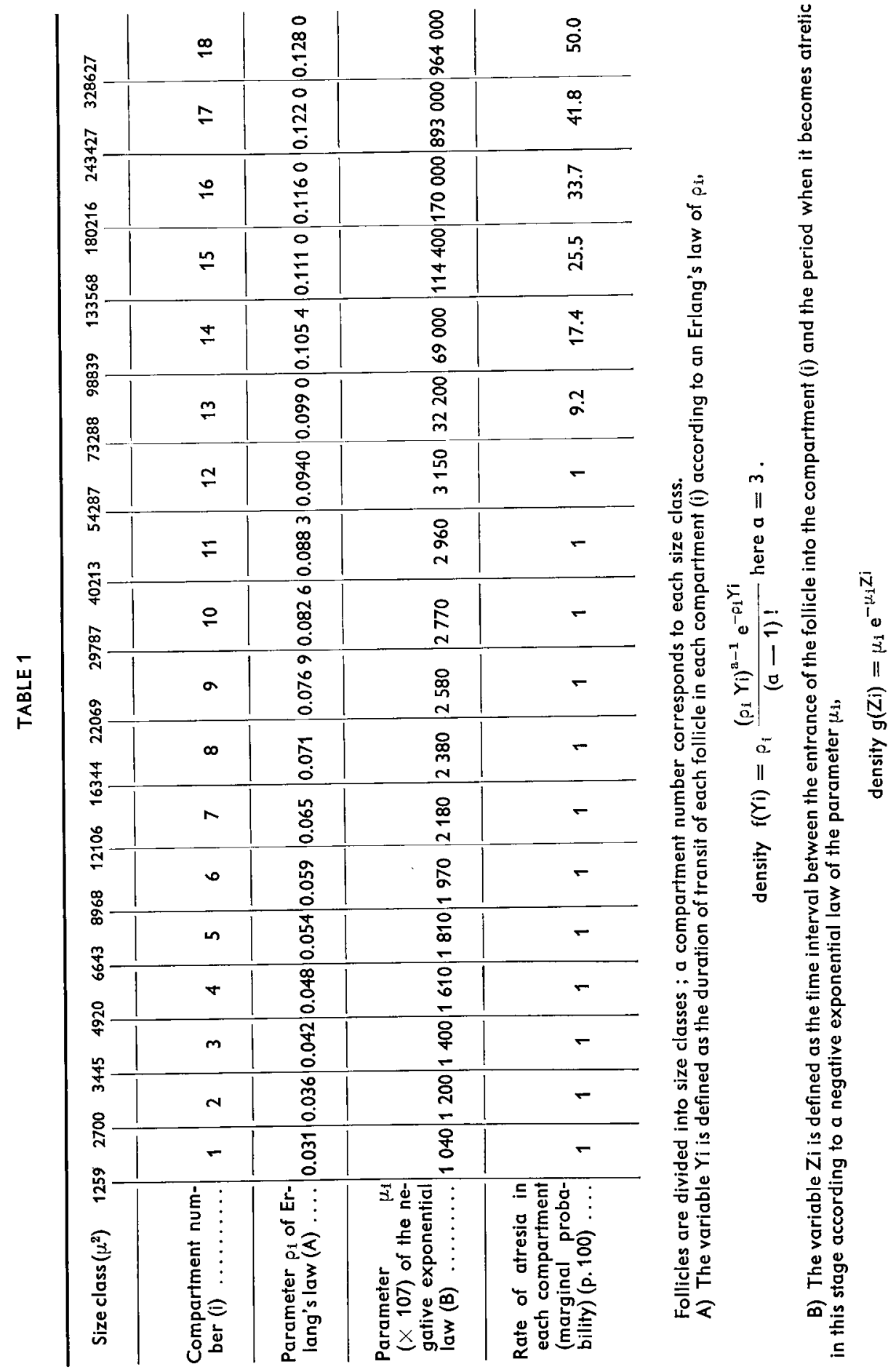


an estimate of the general profile of the distribution of follicles classed according to size, and whether this distribution was comparable with that observed experimentally.

\section{Methodology.}

Follicular growth was divided into 18 stages corresponding to a geometric progression of size intervals of the order of 1.37 ; the initial size of the follicle was $1259 \mu^{2}$, and the final size was $588,309 \mu^{2}$.

The follicular growth curve was of an exponential type : its coefficient increased exponentially as a function of follicle age.

This choice was influenced by the results of Pedersen (1969) which suggested that the time for doubling the number of follicular cells decreased as the size of the follicle increased. In addition, we assumed that in each of the 18 stages there was some probability that the follicle would become atretic.

The corresponding event depended on the respective values of two variables, $Y_{i}$ and $\mathrm{Zi}$ (Read and Ashford, 1968). Yi was defined as the possible transit time of the follicle through stage $i$, knowing that it was normal when it passed through the stage, $i-1$; this variable was assumed to follow a third-order Erlang's law (table 1). Zi was defined as the time interval separating follicle entry into stage i from

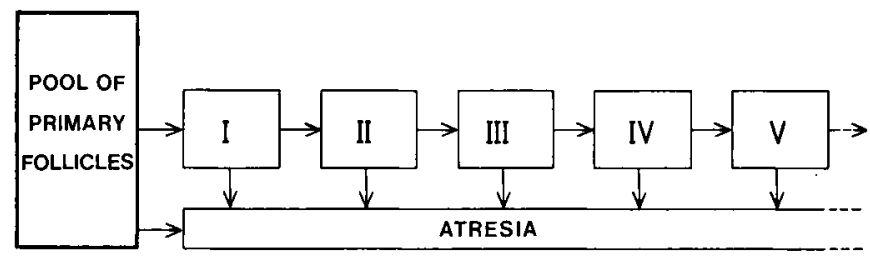

$1^{\text {st }}$ MODEL OF FOLLICULAR GROWTH

FIG. 1. - Primordial follicles with less than 10 follicular cells; they leave the pool and go through the following compartments (I, II,...) according to a Poisson distribution.
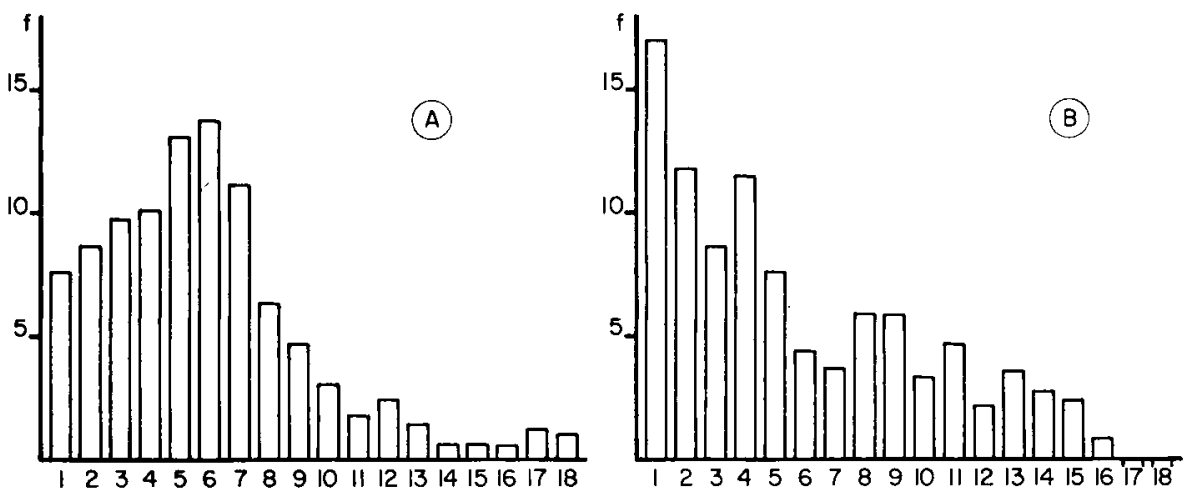

FIG. 2. - A) Follicular distribution in each stage in an adult female rat at 3 months. B) Result of a model 1 simulation (Abscissa : each step represents each follicular size class). 
the time it could become atretic in that stage; this variable was assumed to follow a negative exponential distribution (table 1 ).

Under these conditions, during each transition from one compartment to the next, the follicles left the system by atresia each time that a random choice led to a value of $\mathrm{Z} i$ less than that of $Y_{i}$. In the reserve situation, each follicle spent a time $Y_{i+1}$ in the next compartment.

These functional rules were programmed by means of the GPSS simulation language described in detail by Gordon (1975). They have given rise to two simulation series corresponding to the two following diagrams.

Model 1. - Initially we assumed that follicles left the follicle reserve of less than $1259 \mu^{2}$ and entered the first compartment according to a Poisson distribution (one follicle about every $33 \mathrm{hrs}$ ), and that the follicle reserve was unlimited. The numerical estimates of the parameters of each law of probability were based on experimental data obtained from young female rats at the onset of folliculogenesis during the first 30 neonatal days.

The results obtained differed substantially from the experimental data, whatever values were attributed to the model parameters. For example, in an adult rat the number of follicles in successive compartments appeared to decrease according to the simulation, while in fact, they reached a maximum (fig. 2) corresponding to class 6. This observation led us to reconsider either the profile of the growth curve or the concept of the regulation of the primordial follicle stock.

The latter hypothesis seemed the most plausible in view of recent results obtained by Mariana (1978). We have shown that the probability of a follicle with less than 40 follicular cells (rat) beginning growth by follicular cell multiplication, increased with the initial number of cells surrounding the oocyte. The true utilisable population is formed shortly after birth, and is severely reduced by atresia during the first 30 neonatal days of the female (Jones and Krohn, 1961). The size distribution of these follicles corresponded to the first mode of follicle size distribution up to 30 days (fig. 3). The second mode of the curve corresponded to the follicle population already growing (fig. 3).

The first mode decreased progressively ; it was no longer apparent in the adult rat, and a single mode of growing follicle distribution was observed.

Model 2. - We attempted to simulate a model for the renewal and growth of follicles from two types of stocks (fig. 4). The stock called reserve 1 corresponded to small follicles with less than 5 follicular cells (less than $1259 \mu^{2}$ in size and rarely mobilizable), and reserve 2 included follicles with an exit probability which increased with their size.

We have described in outline four types of follicles in the second reserve. The number of follicles of each type was limited, and the follicles in each category were characterized by an aptitude for growth initiation which augmented as the initial size of the follicle increased (fig. 4).

To illustrate the simulation, we assumed that one follicle left reserve 1 about every $33 \mathrm{hrs}$, and that the mean starting frequencies for each of the 4 types of follicles in reserve 2 were one every $3 \mathrm{hrs}$, one every $75 \mathrm{~min}$, one every $60 \mathrm{~min}$ and one every 45 min, respectively. 


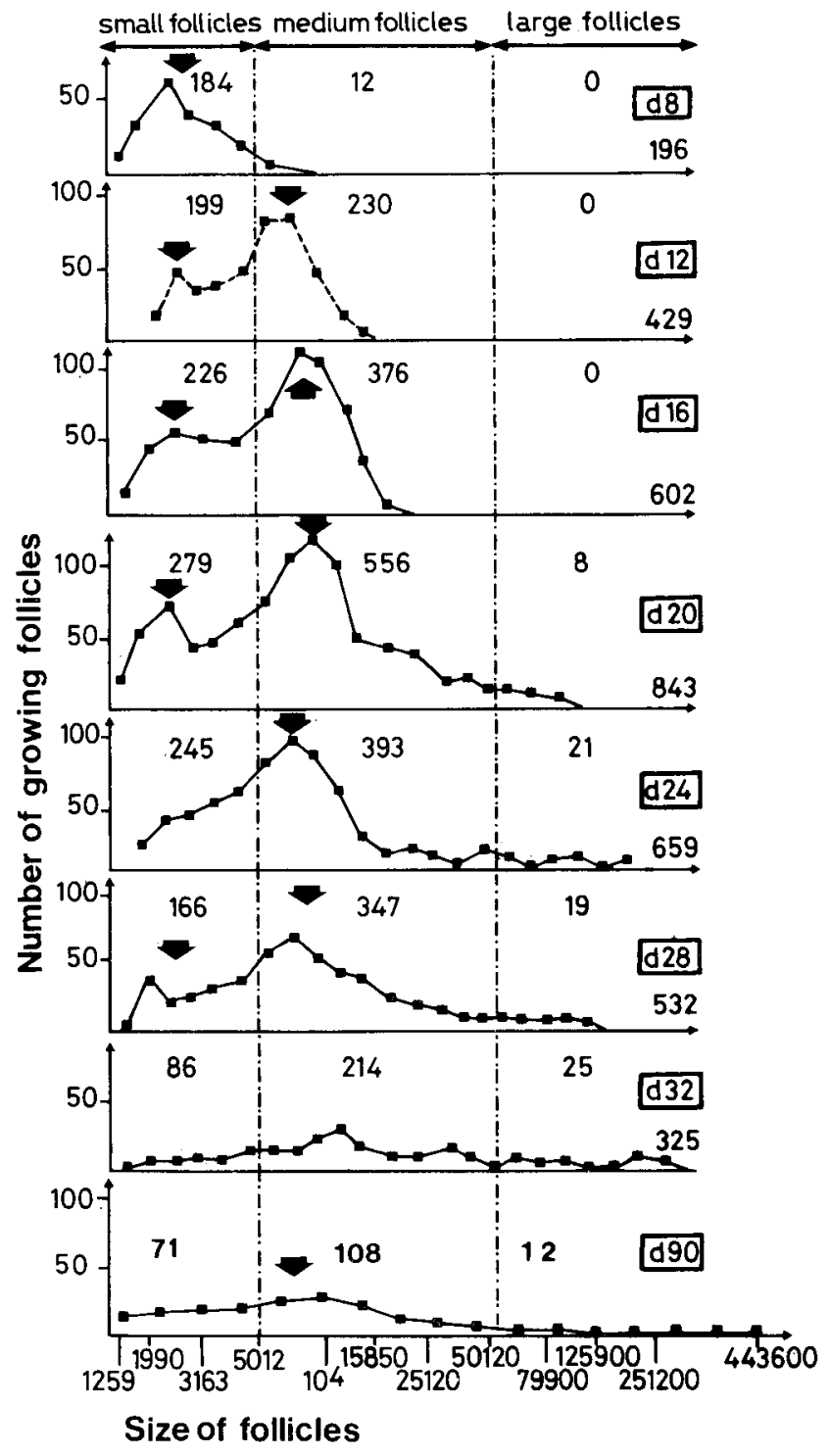

FIG. 3. - Follicular size distribution befween 8 and 90 days after birth in the female rat (from de Reviers, 1974). The distribution curve is bimodal until 20 days. The first mode corresponds to the small follicles (1st arrow) and disappears at about 24 days. Thus, we can observe only one mode corresponding to medium follicles (2nd arrow). On this graph, we have not represented the distribution of follicular sizes less than $1259 \mu^{2}$. 


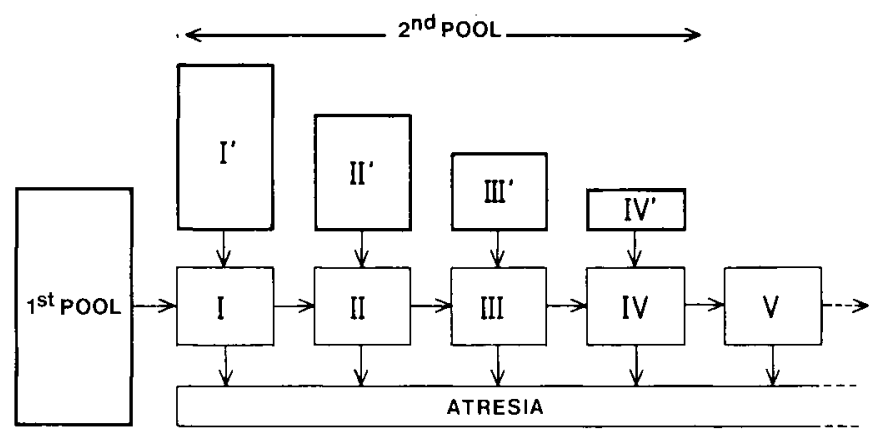

$2^{\text {nd }}$ MODEL OF FOLLICULAR GROWTH

FIG. 4. - Follicles can initiate their growth from the first pool or from the different compartments $\left(\mathrm{I}^{\prime}, \mathrm{II}^{\prime}, \mathrm{III}^{\prime}\right.$, IV') of the second pool. The first pool contains primordial follicles with less 10 follicular cells (follicles of less than $1259 \mu^{2}$ ) ; the second pool contains follicles with between 10 and 40 follicular cells. The size of compartment $I^{\prime}$ follicles is between 1259 and $2700 \mu^{2}$, and they begin growth in compartment I. Follicles of compartment II' are between 2700 and $3645 \mu^{2}$ in size and initiate their growth in compartment II...
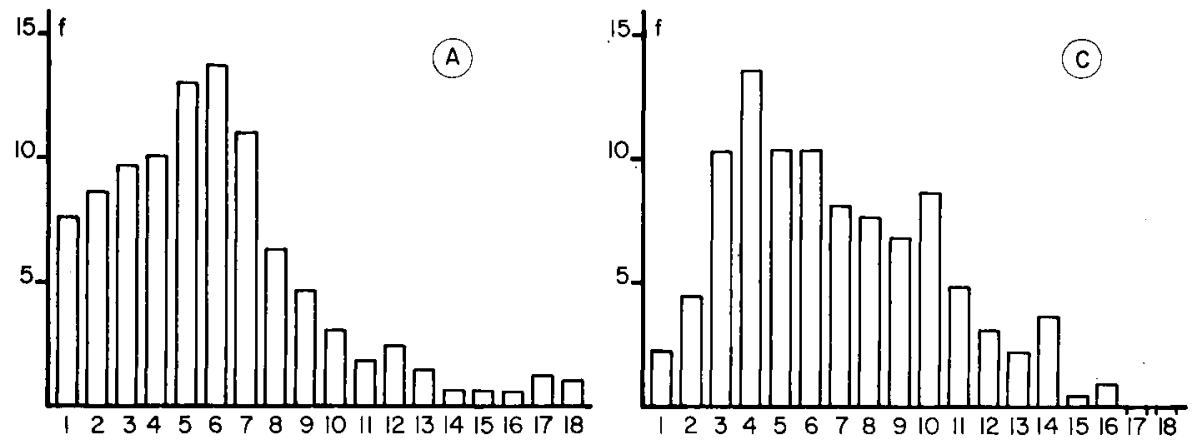

FIG. 5. - A) Follicular distribution in each stage in an adult femole rat af 3 months.

C) Result of a model 2 simulation (Abscissa : each step represents each follicular size class).

The histogram profile obtained by simulation approached that of the experimental histogram obtained in the adult rat (fig. 5). Simulation is in no case a method of adjustment, and it is difficult to attempt a numerical comparison since the prohibitively large number of parameters in the model made such an adjustment unwieldy.

\section{Conclusion.}

One of the purposes of mathematical models in biology is to summarize the information contained in the experimental data as a number of quantified parameters, and to ultimately allow a comparison of different biological situations. The disadvantage of these models is that they may sometimes present a static summary of the dynamic situation which the biologist has to deal with : the biologist can only question the 
validity of the model, the descriptive quality of the parameters, and their efficiency in reconstituting the initial dynamics.

The analytical study of a mathematical model is sometimes difficult and, even when considering a minimum number of size classes to account for growth, the number of parameters to be calculated is large and can only be satisfactorily estimated if a sufficient number of experimental data are used. The result is the dilemma of a credible model which it is almost impossible to verify.

Simulation techniques can, however, be of great help. On the one hand they allow the kinetics of a model to be followed in time, and its pertinence or defects to be evaluated at any moment; on the other hand, they permit the testing of new sub-hypotheses.

The plasticity of the compartmental model proposed by Read (1968) led to the demonstration that it was difficult to retain the possibility of a unique, homogeneous reserve of primordial follicles.

The distribution of growing follicle size observed in an adult female rat can only be explained by the existence of two follicle reserves, the first consisting of follicles having less than 10 follicular cells, and the second of follicles with between 10 and 40 follicular cells.

Follicles begin growth essentially from the second reserve, which is constituted in the rat during the first three neonatal weeks. The new problem which these results suggest is that of the estimate of the reserve follicle population which conditions follicular growth. This question has been studied by Read et al. (1979) in the young.

The numerous parameters of a model such as the one we have presented cannot be estimated using simulation methods. However, these methods may be used to quantitatively test biological hypotheses, and we consider that they can orientate the elaboration of sub-models.

EEC Seminar on « Ovarian stimulation and egg quality in mammols », Luynes, France, octobre 1978.

Acknowledgements. - The authors thank Dr. Meredith Lemon for her help in preparing the English translation.

Résumé. En utilisant les méthodes de simulation appliquées à deux modèles mathématiques, nous avons tenté de montrer que l'existence d'une réserve unique de follicules ayant moins de $1259 \mu^{2}$ n'était pas compatible avec la structure de la population des follicules observée chez l'animal adulte. Par contre, une réserve où on distingue plusieurs catégories de follicules selon leur taille ef leur aptitude à démarrer leur croissance rend compte de la structure unimodale de la population des follicules en croissance chez l'adulte.

\section{References}

FADDY M. J., 1976. A note on the general time dependent stochastic compartment model. Biometrics, 32, 443-448.

FADDY M. J., JONES E. C., EDWARDS R. G., 1976. An analytical model for ovarian follicle dynamics. J. exp. Zool., 197, 173-186.

GORDON G., 1975. The application of GPSS $V$ to discrete system simulation. Prentice Hall. 
JONES E. C., KROHN P. L., 1961. The relationships between age, numbers of oocytes and fertility in virgin and multiparous mice. J. Endocrinol., 21, 469-495.

MARIANA J. C., 1978. Analyse biométrique de l'index de marquage des cellules folliculeuses et de la taille des ovocytes des follicules primordiaux d'ovaire de rate adulte cyclique. Ann. Biol. anim. Bioch. Biophys., 18, 1333-1342.

MARIANA J. C., MILLIER C., 1977. Application de quelques modèles de dynamique des populations à l'étude de la folliculogenèse ovarienne. Ann. Biol. anim. Bioch. Biophys., 17, 193-206.

PAESI F. J. A., 1949. The influence of hypophysectomy and of subsequent treatment with chorionic gonadotrophin on follicles of different sizes in the ovary of the rat. Acta endocrinol., 3, 89-104.

PEDERSEN T., 1969. Follicle growth in the immature mouse ovary. Acta endocrinol., 62, 117-132.

READ K. L. Q., 1968. Some problems in applied statistical estimation. Ph. D., Univ. of Exeter.

READ K. L. Q., ASHFORD J. K., 1968. A system of models for the life cycle of a biological organism. Biometrika, 55, 211-221.

READ K. L. Q., MARIANA J. C., DE REVIERS M. M., 1979. Some statistical models for ovarian folliculogenesis. Ann. Biol. anim, Bioch. Biophys., 19, 1419-1433.

REVIERS M. M. de, 1974. Etude quantitative de l'action des hormones gonadofropes hypophysaires sur la population folliculaire de l'ovaire de rate immafure. Signification biologique du dosage de l'hormone folliculostimulante par le test de Steelman et Pohley. Thèse Univ., Tours. 